\title{
Development Communication
}

\author{
Fatemeh Deilamy \\ PhD student of journalism from people friendship university of Russia. \\ *Corresponding Author, Email: deilamyf@gmail.com
}

\section{Barmak Bayat}

PhD student of journalism from people friendship university of Russia

\author{
Doi:10.5901/mjss.2015.v6n6s6p361
}

\begin{abstract}
Any emerging scientific field is facing with challenge of explaining concepts and the theoretical realm of its unique concept or in other words science identity which communications and development is such. So, in this article, we are going to review methods and library explaining concepts and pay to offered different approaches at the communication development area and meanwhile getting attention of readers pointed out the importance of it and with the introduction of barriers to the development communication, strategies and scientific recommendations on the use of it, according to cultural condition and socializing in our country should be provided. In this study, the role of the press, particularly in development communication is studied. The most important thing is to study the role of the press in the development of these communication .
\end{abstract}

Keywords: development, communications, press, technology.

\section{Introduction}

Communication in today's age plays a key role in determining the fate of developing countries and this means are the source of many contemporary developments, guide and control the flow and changes in the world. In our era, change is considered normal and the world goes towards a global village and in the pouring system and national organizations and at the same time budding challenges and new crises in the areas of politics, culture, economy, security, and so. According to Mcluhan, communication media (such as newspapers) are in place to eliminate and like a village, all the people from an event that occurs in a corner of the world, will be notified. Thus, the communication recognition, rate and around communications of media with events and global developments deemed to be necessary and therefore many scientists have done a lot researches and surveys (Aghili and Tatary, 2012).

In the new world order, we live in a media age, an age where mass media are an integral part of our lives. Communication with different media policies facilitate and accelerate cultural development of countries. The function of the media in the age of communication is undeniable certainly in all aspects of social life and a culture of human society. Today, society is considered a developed society that along with the development of social indicators and the economy such as per capita income, GDP distribution, mortality rates stress on the standard of education and information and knowledge of social (kazemzade and Kouhie, 2010).

Theories for DEVELOPMENT COMMUNICATION was completed gradually at ITU so that in the late 1990s, the subject of communication and development are as the main issues of this EU and with the advent of the Internet and spreading the information highway each day on the added role. Today, the concept of the information society, the information revolution is located on the communications platform and all countries in the world in close challenge, to seek new methods of communication (Aghaee, 2011).

According to the mentioned approaches to the press and the role that they can have at development communications

and information technology, in this study the role of the press as an important tool in the development will be analyzed, but originally said History of communications and factors and obstacles in the way of its development, strategies to help achieve the objectives of this section to the press is presented. 


\section{Theoretical Framework}

\subsection{Development}

Today in the society, national development plans (endogenous) based on the capabilities and infrastructure of communication and culture which play a key role in social development, are developed. But all development programs are not endogenous type. To governments and decision makers is recommended that as far as possible the development programs of other countries (exogenous programs) must be investigated and primarily in the technology section and communications invest in the body of cultural diversity (Bakhshandeh and Khaniki, 2007).

Development is a very complex concepts which is end of all programs, efforts and actions of human societies. The existence of different aspects of development indicates the complexity of it. Development is a multidimensional process and planned to provide space for humans in order to have a healthy life, creative and effective (Taleb Bidokhti, 2013).

In other words, the development is effort to create a balance unrealized or a solution for decompression and the problems continued between different sectors of social life and human. Development is a path which in itself, renewal and bring different direction of whole socio-economic system. This is in addition to have improvements in production and income and fundamental change and building institutional, social, administrative, communications and also, public comments will be included.

Development in many cases covers even habits and customs and public opinion. Scholars believe that development is multidimensional which included economic dimension, social, cultural, political and human. Today our concept of this process is comprehensive, focused on improving people's lives society (Aghili and Tatary, 2012).

Regardless of the time, the development of society particularly for democratic development is another factor in increasing public awareness at the political field, economic, social, and medical and... which have many roles. (Katz, 2006).

\subsection{Communications}

Imagine a world where does not exist the "Communication" in this world human living alone and single and never have participation for accumulating experience and science and never to overcome the difficulties and personal constraints cannot have unity and integration. Do not share in patents, the chance will not be a lot of benefit, in such a world, human cannot accept the influence of others in a way and affect cross. In other words, imagine such a world, if not impossible is difficult. Communications according to the definition in the Oxford English Academy comprehensive is the sending, transmission and exchange of ideas, knowledge and so on.

Western researchers are available founders of new ideas and methods and communication techniques, believe that the Word communication from the Latin word (Communicare) is derived; the word in Latin means To Make Common; or public and or in other words is public. This means that is the concept of individual arose extended among others and have been moved to others. So in principle it is believed that communications, some concepts and thoughts and meanings or in other words expand messages to others or the public. Newer definitions of the "exchange concepts" and or" exchange meaning" and is also" exchange or transmit messages" they (Khoi nejhad, 2007).

Yet could not find scientific evidence and attributable to suggest that the first human contact at what time and in what place with what process is established. But human to be used at many centuries handwriting, to transfer knowledge and information and beadles also in the oral communications equipment ruling pay the role. Then, the letters were discovered and metal industry was developed to news on the paper and newspapers were used as one of the most important communication technologies. As well as publishing stores sales generated book. After this social move, human communication have different prominence in society. Finally, the scope of written communications instrument and as a result increased growth areas of communication science. So that in the 16 th century to 20 , millions of books published in Europe.

Another development that took place in communication science was the operation of the electronic media which with the invention of radio has entered a new phase. In the electronic age, the world gathered in the "global village" and causing the human deep connection. During the 1960s and 1970 with the spread of television, also spread the use of these devices and the development of communication smoother and more spacious (Mortazavi Rad, 2013)

Lasswell several tasks such as taking care of the environment, solidarity between the various components of society in response to the environment which takes place the cultural heritage transmission from generation to other generation, considered the main tasks of mass communication (Lasswell, 2007).

Communication is as one of the most important management process element. The existence of effective 
communication and correct is one of the important components in the success. Experience has been proven that if communication is not established correctly, the impaired circulation and things are chaotic. Coordination, planning, organization, control and other duties not be achieved without effective communication system and will not be possible to manage. Communication leads to power and a means to apply the proper legal authority, administrative and applied it, the development of communications media goes in parallel with the development of modern society such as schools, industry, closely related to some social development indicators, general economic, such as literacy, per capita income and urbanization (Ramaseshan, 2006).

Advanced communications along with the deep effects of political and economic are changing in the world. In Islamic countries of the Middle East introduce the relationship between communications in general and telecommunications in particular required modernization and the development of the way the government wants (Molana, 2002)

Communication have effective role in the increasing knowledge, individual awareness especially in today's world give to person the comparison power and choose. In modern societies in order to achieve its objectives work in the field of national and international, using mass media such as radio, television, press, cinema and satellite technology, and telecom form public opinion according to his goals (Liaghatdar, 2009).

Analysts Overall consensus on the fact that the communication is played the main role of the growth engine in the past three decades around the world, some are even a step further, the current era of human life is called age of communication. Link three factors: technology, information, management aims to create new functionality in the businesses management methods and empowering managers to take advantage of information technology and communication have great impact on the success of knowledge-based development programs (Najafizadeh, 2014).

\subsection{Communication from the Viewpoint of Different Schools of Management}

Classical theorists have defined communications as written documents and command authority (Weber, 1947), the flow of messages and encourage employees (Taylor, 1947), the horizontal flow of information (Fayol, 1949), listening and unofficial communication (Rotliz Berger, 1941), feedback and behavior established (Follett, 1941) and obligations arising from the decision (Barnard, 1968). (Putbam, 2002)

According to the initial trend of researchers about type of communications orientations in the mid-twentieth century four research create areas include:

1) Communication channel

2) Communication content

3) Communication style

4) Communication path (Jablin, 2001)

A summary of the communication component differences in approaches to human resource, human relations and classical shown in the following table:

Table 1. differences of communication components in the views of management different schools

\begin{tabular}{|l|l|l|l|}
\hline Communications axis & The classic approach & Human relations approach & Human Resources Approach \\
\hline Communication channel & Functional & Duties and social & Duties, social and innovative \\
\hline Communication content & Vertical & Vertical and horizontal & All routes, group \\
\hline Communication style & Written & face to face & All channels \\
\hline Communication path & Official & unofficial & both of \\
\hline
\end{tabular}

Media in addition to extension and fast of data transfer to an audience have more interactive features withe audience and the more access information and ease of access (Katz, 2006)

Mass media like the press as a social institution with other institutions in society have mutual trade relations. No doubt this social institution an important factor to be considered in the process of social change, economic growth. Communications in general means reflect political structures, economic, and cultural in a determined society. In the framework of such structures is that social interaction among people and finally occurs participation. In fact, it can be said that the process of developing have lasting relationship with the interaction between people and the active participation of social different groups. This will not happen unless in the light of a comprehensive system of communication which can largely resolve conflicts, contradictions in people's values and behaviors and providing a favorable environment for national development which effective (Rahmanzadeh and Ghaffari, 2011). 


\subsection{Factors and Effecting Barriers in the Development Communication}

In developing countries like other countries, communications technologies and information in general and the Internet and the World Wide Web specifically is growing but the increase in productivity, efficiency, effectiveness and other benefits of the IT revolution because of cultural field and socializing and the lack of attitude and the skills required are briefly described in the introduction, is still unrealized. Hence, it seems, communications in this category of countries actually have not become a social movement. The government in developing countries as well as other social sectors will follow such results, the responsibility to promote development objectives in the field of science and technology in the structural disability and human and lack of resources and social infrastructure and software.

This responsibility burden since more weight on the Third World governments which in addition to efforts that for reform and internal modernization and manufacturing system integration and the distribution of information through communication technology and information to operate, social trends must be monitor on a large scale and great and facilitate and strengthen fields and the human context, social and cultural to development of modern information technology use in the community level.

In other words, governments in the Third World on the one hand have to mail the decisions, regulations, rules and administrative affairs of government in the management dimension and programmatic and executive. On the other hand have the external aspect and social, we must promote, coordinate, reform goals and processes, recovery of consulting services and restructuring in the control and monitoring of social, economic and ultimately set the stage for increased access and moreover people and community institutions to communications. The development obstacles of the state and public sectors in the community are based on the information and network which divide into three main category " infrastructure barriers and hardware", "knowledge - skills" and "cultural and social".

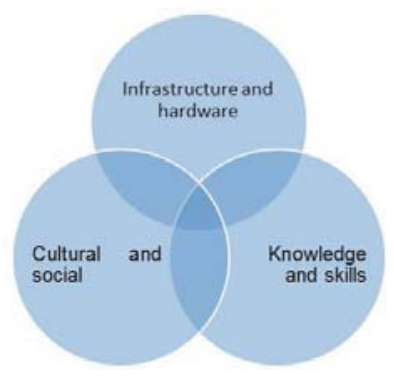

Figure 1. Communication development obstacles (William, 2005)

\subsubsection{Barriers related to infrastructure and foundation}

These obstacles are hardware and infrastructure and to advances in communications engineering, electronics, computer engineering and its related instruments as well as specialized capabilities and skills of human resources in managing, planning and reform and improve the system and communications networks including the infrastructure case of foundation is considered.

\subsubsection{Barriers related to knowledge and skill}

Information literacy based on the skills related to language and computer, the main core of logging to community based on the information. Deep understanding and extensive of staff, planners, experts and managers from the data and information in planning, monitoring and evaluation of activities as well as do not have the necessary skills to access and use information systems, computers, internet and other capabilities on network, behind backwardness of an organization, a government or a community compared to others. Such a situation easily creates a vicious cycle. In the current situation, employees, experts and managers to information and organized knowledge not care and this cause areas for do not up to date information and poor information in an organization or social institution. These two issues, basic factor to lack of knowledge and information, because information is obtained and exist in the system due to "no value" and "lack of quality" in the process of reform and modernization organizations such as governmental, public and private will not be used (Robbins, 2001). 


\subsubsection{Cultural and social barriers}

Social transformation to increase the use and the use of information technology and play an active role in the international community based on information when will form which policymakers and decision makers and top managers a positive attitude and motivation and have enough understanding of the role and Functionality of communication technologies and information. Also, to achieve this goal, knowledge, readiness, ability and skills of employees and experts of the administrative bodies, socio-economic, cultural and education is necessary (Williams, 2005).

While the review and re-engineering government role in promoting society based on the information and communication developed space helping to improve society attitudes, create desire and interest in access and utilization of information networks in economy, business are the responsibility of the state particular in countries such as Iran. As well as capacity building, increase the knowledge, skills, and empower of society individuals and support and strengthen "public institutions", "Private Sector" and "civil society" are the strategies that government must make fulfill in order to plan and wide actions effective.

\section{Conclusion}

Development and communication have close links with the culture and human civilization (Estiveson, 2003), in fact this two concept are very close to each other which resulting loss of one affects the other one. (Bakhshandeh and Khaniki, 2007). Therefore, for development communication should be at the first stage, done development at the national level, because this subject provides the background and the necessary conditions for development in all fields, including in the field of communication.

On the other hand, given that the rate of arrival of new technologies on human life today is very high and each with new features are affected a part of life. Economy, culture and politics by the impact of community has taken a new form. Do not introduce to the public a technology, another technology is introduced to society and the press to introduce the use of communication to the public has essential role (Aqaee, 2011). It must be used powerful tools for develop the communication which as stated one of the most powerful tools are press. But what is certain is that, given the constraints affecting on the development of communication which noted in this article, in the meantime means of communication, the media have an important role in the development of communications.

Some of these roles are:

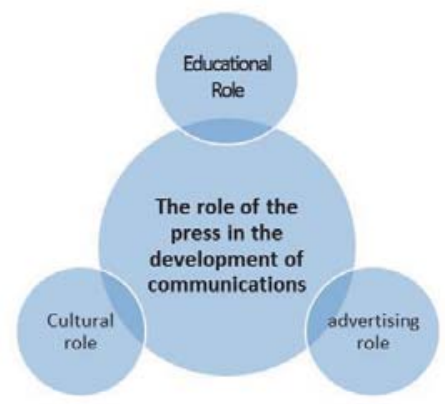

Figure 2: The role of the press in the development of communications

- The educational role of press can be reflection of applications, how to use the service and its impact on people society to take advantage of this teach service.

- The culture role of press can learn to people the correct method of use the media and the communications services and information technology and can spread its use correct.

- The advertising role of press can with the release of the positive effects of the application of communications, to encourage people to use these services.

Finally, it seems, as Justice (1385) also confirmed that, despite the opposition of the lifestyle and values of the Islamic republic and the West, Iran is pursuing the technology and capital of the West, to the Community to expand and develop. Development communications and media on the one hand, contributes to the formation of human character and, on the other hand, governments and communities are ready to accept the values and culture will therefore seems 
necessary to develop and, In this regard, the press can be a facilitator role, the role of education, culture and communication in the country contributed to the development of the promo.

Finally, it seems, as Dadgaran (2006) also confirmed that, despite the opposition of the lifestyle and values of the Islamic republic and the West, Iran is pursuing the technology and capital of the West, to expand and develop communication. Development of communications and media on the one hand, to contributes for the formation of human character and on the other hand will ready the governments and communities to accept the values and culture therefore seems necessary to develop and in this regard, the press can be a facilitator role and by the role of education, culture and promo to the development the communication in the country contributed.

\section{Reference}

Aqaee, Bahman, Bigelow, Maryam. (2011). The role of the press in the development of ICT in Iran. Thesis, University of Allameh Tabatabai.

Bakhshandeh, Ehsan, Khaniki, Hadi. (2007). Community development, translations and culture. Journal of Translation Studies, Vol. 5, No. 18, pp. $62-50$.

Khoinejhad, Gholamreza. (2007). The relationship between the effectiveness of corporate communications and power resources managers, seven educational institutions in the academic year 2005-2006 Mashhad. Management Education Management and Planning Organization of Khorasan Razavi province.

Robbins, Stephen P. (2001). Organizational behavior. Tehran: Cultural Research Bureau.

Rahmanzadeh, Ali, Ghaffari moin, Zahra (2011). The Role of the national media in the development of cultural relations between the ethnic groups from the perspective of experts. Journal of Media Studies, Vol. VI, No. XIII, pp. 249-223.

Dadgaran, Mohammad. (2006). Development and communication. Journal of cultural universe, No. 237, p. 22.

Aghili, Vahid and Tatary, Khadija. (2011). the role of national identity in the Development of Communication. Culture Communication Quarterly, Issue V, pp. 92-71.

Talib Bidokhti, Abbas. (2013). Review the strategic role of social capital in economic growth and development. Research project, Department of Islamic Azad University Gachsaran.

Liaghatdar, Mohamad Javad, Naqvi, Fataneh, Yazdkhasti, Behjat, Samii, Fatemeh. (2009). the impact and role of cultural attitudes, Family and Community Development tendency of women to higher education. Journal of Applied Sociology, the twentieth year, No. 33, No. 1, pp. 82-71.

Kazem Zadeh, Moses, Kohie, Kamal (2010). the role of culture in the development of new means of communication, barriers and solutions. Cultural RESEARCH, VOL, pp. 210-184.

Mortazavi Rod, Mercede. (2013). Examine the role of non-verbal communication with an emphasis on color element in the behavior of consumers shopping online website. Thesis, Tehran University Kish International Campus.

Maulana, Hamid. (2002). Community development policy in Iran. Journal of cultural universe, No. 196.

Najafizadeh, Hossein. (2014). the effect of information technology on the quality of staff training and stamp Lamerd County municipalities. Master's thesis, Islamic Azad University, Lamerd

William, H., Datn. (1384). Social change in the information society. Translated by: Mohamad Tavakolt and Ebrahim Kazmipor, Tehran: National Commission for UNESCO (the date of publication in the national language, 2005)

Jablin, F.M \& Putnam. L. (2001). The new handbook of communication for commitment in remote technical workfoces. journal of communication managment, 10, 353-370.

katz- Helen e. (2006). The Media handbook:a complete guide to advertisingmedia selection business \& economics. p183.

Lasswell (H.D).(2007). The structure and function of communication in society, p: 118.

Putbam. L. (2002). Methaphord of communication and organization, handbook of organization studies, cligg. C hardy, pp. 18-20.

Ramaseshan, B and Yip, Leslie S.C.and Pae, Jae H (2006). Power, Satisfaction, and relationship Commitment in Chinese Store-tenant relationship and their impact on performance. Journal of Retailing.

Stevenson, Robert L. (2003). National Development and Communications, Encyclopedia of International Media and Communications, Pages 163-175. 